\title{
Development and Evaluation of Multiplex PCR for the Detection of Carbapenemase-Producing Enterobacteriaceae
}

\author{
Si Hyun $\mathrm{Kim}^{1 *}$, II Kwon $\mathrm{Bae}^{2 *}$, Na Young $\mathrm{Kim}^{3,4}$, Sae Am Song ${ }^{3}$, \\ Sunjoo Kim ${ }^{5}$, Joseph Jeong ${ }^{6}$, Jeong Hwan Shin ${ }^{3,4}$
}

\begin{abstract}
${ }^{1}$ Department of Clinical Laboratory Science, Semyung University, Jecheon, ${ }^{2}$ Department of Dental Hygiene, Silla University, ${ }^{3}$ Department of Laboratory Medicine, Inje University College of Medicine, ${ }^{4}$ Paik Institute for Clinical Research, Inje University College of Medicine, Busan, ${ }^{5}$ Department of Laboratory Medicine, Gyeongsang National University College of Medicine, Jinju, ${ }^{6}$ Department of Laboratory Medicine, Ulsan University Hospital, University of Ulsan College of Medicine, Ulsan, Korea
\end{abstract}

\begin{abstract}
Background: The isolation of carbapenemase-producing Enterobacteriaceae (CPE) has become increasingly common. Continuous surveillance for these organisms is essential because their infections are closely related to outbreaks of illness and are associated with high mortality rates. The aim of this study was to develop and evaluate multiplex PCR as a means of detecting several important CPE genes simultaneously.

Methods: We aimed to develop a multiplex PCR that could detect seven CPE genes simultaneously. The multiplex PCR was composed of seven primer sets for the detection of KPC, IMP, VIM, NDM-1, GES, OXA-23, and OXA-48. We designed different PCR product sizes of at least $100 \mathrm{bp}$. We evaluated the performance of this new test using 69 CPE-positive clinical isolates. Also, we confirmed the specificity to rule out false-positive reactions by using 71 carbape-
\end{abstract}

nem-susceptible clinical strains.

Results: A total of 69 CPE clinical isolates showed positive results and were correctly identified as KPC $(\mathrm{N}=14)$, IMP ( $\mathrm{N}=13), \mathrm{OXA}-23(\mathrm{~N}=12), \mathrm{OXA}-48(\mathrm{~N}=11)$, VIM $(\mathrm{N}=9)$, GES $(\mathrm{N}=5)$, and NDM $(\mathrm{N}=5)$ by the multiplex PCR. All 71 carbapenem-susceptible clinical isolates, including Enterococcus faecalis, Escherichia coli, Klebsiella pneumoniae, Acinetobacter baumannii, and Pseudomonas aeruginosa, showed negative results.

Conclusion: This multiplex PCR can detect seven CPE genes at a time and will be useful in clinical laboratories. (Ann Clin Microbiol 2019;22:9-13)

Key Words: Carbapenem, Carbapenem-resistant Enterobacteriaceae, Carbapenemase-producing Enterobacteriaceae, Enterobacteriaceae, Multiplex PCR

\section{INTRODUCTION}

카바페넴(Carbapenem) 항균제는 광범위 베타락탐분해효소 (extended-spectrum $\beta$-lactamase, ESBL)를 생산하는 그람음성 균 감염증의 치료에 널리 이용되고 있다[1]. 최근 ESBL 생성 그람음성균의 확산에 따라 카바페넴 항균제의 사용량이 증가 하였고 카바페넴 내성균 또한 증가하여 전 세계적으로 문제가 되고 있다[2]. 카바페넴 내성은 주로 Pseudomonas aeruginosa 와 Acinetobaacter baumannii 등에서 흔히 보고되었으나 최근 카바페넴 내성 장내세균(carbapenem-resistant Enterobacteria- ceae, CRE)의 분리가 증가하고 있다[3]. 카바페넴 내성 기전 중 카바페넴 분해 효소의 생성에 의한 내성은 플라스미드를 통한 전이가 쉬워 집단발생 가능성이 높기 때문에 빠른 진단 및 지 속적인 감시가 필수적이다[4,5].

카바페넴분해효소 생성균(carbapenemase-producing Enterobacteriaceae, $\mathrm{CPE}$ )은 항균제 감수성 시험만으로는 $\mathrm{CRE}$ 와 감 별할 수 없어 카바페넴분해효소 선별시험 및 확정시험이 필요 하다[6]. CPE는 modified-Hodge 시험(MHT) 및 carbapenemase 억제시험(CIT)을 통한 표현형 시험 또는 유전자 증폭을 통한 유전형 시험으로 검출할 수 있다. 표현형 시험의 경우 결과 확

Received 3 August, 2018, Revised 3 October, 2018, Accepted 4 October, 2018

Correspondence: Jeong Hwan Shin, Department of Laboratory Medicine, Busan Paik Hospital, Inje University College of Medicine, 75 Bokjiro, Busanjin-gu, Busan 47392, Korea. (Tel) 82-51-890-6475, (Fax) 82-51-890-8615, (E-mail) jhsmile@inje.ac.kr

*These authors contributed equally to this work.

(c) The Korean Society of Clinical Microbiology.

(ㄷ) This is an Open Access article distributed under the terms of the Creative Commons Attribution Non-Commercial License (http://creativecommons.org/licenses/by-nc/4.0) which permits unrestricted non-commercial use, distribution, and reproduction in any medium, provided the original work is properly cited. 
인이 주관적이고 내성 유전자 종류를 확인할 수 없는 단점이 있고 위양성의 가능성도 배제하기 어렵다[7,8]. 본 연구에서는 현재 알려진 주요 CPE 내성 유전자를 한번에 검출할 수 있는 multiplex PCR법을 개발하고 이를 평가하고자 하였다.

\section{MATERIALS AND METHODS}

본 연구에서는 카바페넴분해효소 생성 균주의 검출을 위하 여 국내에서 보고된 바 있는 KPC형, GES형, IMP-1형, VIM-2 형, NDM형, OXA-23형 및 OXA-48형을 대상으로 multiplex PCR을 고안하였다. GenBank의 데이터베이스에 등록되어 있 는 각 유전형의 염기서열을 수집하였으며 최종적으로 KPC 아 형 14가지, GES 아형 24가지, IMP-1 아형 12가지, VIM-2 아형 20 가지, NDM 아형 16 가지, OXA-23 아형 18가지, OXA-48 아 형 11 가지를 대상으로 이들의 공통된 염기서열 부분을 이용하 여 primer를 고안하였다. 수집된 각 유전자의 염기서열을 이용 하여 7종의 $\mathrm{CPE}$ 유전자를 한번에 검출할 수 있도록 각 $\mathrm{PCR}$ 산 물의 크기를 설정하였다. 최종 증폭 산물의 크기는 각 유전자 별로 $100 \mathrm{bp}$ 이상 차이가 나도록 고안하여 배치하였고 각 pri-

Table 1. Clinical strains of carbapenemase-producing Enterobacteriaceae used in this study

\begin{tabular}{|c|c|}
\hline Carbapenemase type and species & No \\
\hline GES & 5 \\
\hline Klebsiella pneumoniae & 4 \\
\hline Serratia marcescens & 1 \\
\hline IMP & 13 \\
\hline Enterobacter spp. & 1 \\
\hline Enterobacter cloacae & 2 \\
\hline Pseudomonas aeruginosa & 10 \\
\hline $\mathrm{KPC}$ & 14 \\
\hline Enterobacter aerogenes & 1 \\
\hline Escherichia coli & 2 \\
\hline Klebsiella pneumoniae & 11 \\
\hline NDM & 5 \\
\hline Escherichia coli & 2 \\
\hline Klebsiella pneumoniae & 3 \\
\hline OXA-23 & 12 \\
\hline Acinetobacter baumannii & 11 \\
\hline Acinetobacter nosocomialis & 1 \\
\hline OXA-48 & 11 \\
\hline Escherichia coli & 3 \\
\hline Klebsiella pneumoniae & 8 \\
\hline VIM & 9 \\
\hline Enterobacter cloacae & 1 \\
\hline Pseudomonas aeruginosa & 4 \\
\hline Pseudomonas fulva & 1 \\
\hline Pseudomonas monteilii & 1 \\
\hline Pseudomonas putida & 2 \\
\hline Total & 69 \\
\hline
\end{tabular}

mer 세트와의 교차 반응을 확인하기 위한 시뮬레이션을 수행 하여 시험관 내 반응 오류를 최소화할 수 있도록 하였다.

Multiplex PCR의 증폭 조건은 임상검체에서 분리된 카바페 넴분해효소 생성 균주로 확인된 7주의 $\mathrm{CPE}$ 양성균주로 설정하 였다. 각 양성균주는 Tris-EDTA buffer $250 \mathrm{uL}$ 에 부유시켜 $100^{\circ} \mathrm{C}$ 에서 5 분간 가열하였으며 $-20^{\circ} \mathrm{C}$ 에 옮겨 핵산을 추출하 였다. 추출된 핵산은 유전자 증폭 시험을 위해 사용 시까지 $-70^{\circ} \mathrm{C}$ 초저온 냉동고에 보관하였다. Multiplex PCR은 AccuPower PCR premix (Bioneer, Daejeon, Korea)를 이용하였고 최적의 조건을 맞추기 위하여 Veriti 96-well Thermal Cycler (Applied Biosystems, Foster City, CA, USA)를 이용하여 gradient PCR을 시행하였다. $2.5 \%$ Agarose gel에 $100 \mathrm{~V}$ 에서 40 분간 전기영동 하여 증폭산물을 확인하였고 비특이적 반응 없이 가장 선명하

Table 2. Carbapenem-susceptible clinical strains tested $(n=71)$

\begin{tabular}{|c|c|}
\hline Species & No. \\
\hline Acinetobacter baumannii & 5 \\
\hline Enterococcus faecalis & 5 \\
\hline Escherichia coli & 5 \\
\hline Klebsiella pneumoniae & 5 \\
\hline Pseudomonas aeruginosa & 5 \\
\hline Proteus mirabilis & 4 \\
\hline Enterobacter aerogenes & 3 \\
\hline Enterobacter cloacae & 3 \\
\hline Citrobacter freundii & 2 \\
\hline Citrobacter koseri & 2 \\
\hline Citrobacter youngae & 2 \\
\hline Klebsiella oxytoca & 2 \\
\hline Providentia rettgeri & 2 \\
\hline Raoultella planticola & 2 \\
\hline Serratia marcescens & 2 \\
\hline Sphingomonas paucimobilis & 2 \\
\hline Streptococcus pneumoniae & 2 \\
\hline Acinetobacter lwoffii & 1 \\
\hline Acinetobacter ursingii & 1 \\
\hline Burkholderia cepacia & 1 \\
\hline Cryptococcus neoformance & 1 \\
\hline Candida albicans & 1 \\
\hline Candida tropicalis & 1 \\
\hline Citrobacter braakii & 1 \\
\hline Corynebacterium striatum & 1 \\
\hline Enterococcus casseliflavus & 1 \\
\hline Enterococcus faecium & 1 \\
\hline Enterococcus hirae & 1 \\
\hline Morganella morganii & 1 \\
\hline Proteus vulgaris & 1 \\
\hline Providentia stuartii & 1 \\
\hline Pseudomonas fluorescens & 1 \\
\hline Salmonella group D (Vi-) & 1 \\
\hline Staphylococcus aureus & 1 \\
\hline Staphylococcus epidermidis & 1 \\
\hline Total & 71 \\
\hline
\end{tabular}


고 정확하게 나온 조건으로 선정하였다.

고안된 multiplex PCR의 성능을 평가하기 위해 총 69주의 카 바페넴분해효소 생성 균주를 이용하였다(Table 1). 시험대상균 주는 내성 유전자별 KPC 14주, IMP 13주, OXA-23 12주, OXA-48 11주, VIM 9주, GES 5주, NDM 5주가 포함되었다. 비특이적 반응 및 위양성의 확인을 위해 총 71 주의 카바페넴 감수성 균주를 대상으로 평가하였다(Table 2).

\section{RESULTS}

본 연구에서 개발한 multiplex PCR에 포함된 총 7종의 카바 페넴분해효소 유전자의 primer 서열과 유전자 크기는 Table 3 과 같고 $\mathrm{PCR}$ 조건은 $94^{\circ} \mathrm{C} 5$ 분, 30 회 반응 $\left(94^{\circ} \mathrm{C} 30\right.$ 초, $60^{\circ} \mathrm{C} 20$ 초, $72^{\circ} \mathrm{C} 30$ 초), $72^{\circ} \mathrm{C} 7$ 분으로 설정하였다. 본 연구에서 수행한 primer 및 $\mathrm{PCR}$ 조건으로 7종의 내성 유전자에 대한 확인 시험 을 수행한 결과는 Fig. 1과 같다.

총 140 주의 $\mathrm{CPE}$ 양성균주 및 음성균주를 대상으로 개발된 multiplex PCR을 평가한 결과 모두 검출하였고 비특이적 반응 도 확인되지 않았다. 본 연구에 이용된 $\mathrm{CPE}$ 양성 및 음성균주 는 2014년부터 2017년까지 부산백병원에 임상미생물검사가 의 뢰되어 분리된 균주 및 강남세브란스병원에서 분양받은 균주 를 이용하였다[9,10]. 고안된 multiplex PCR의 성능 평가를 위 해 KPC 14주, IMP 13주, OXA-23 12주, OXA-48 11주, VIM 9주, GES 5주, NDM 5주를 포함한 총 69주의 $\mathrm{CPE}$ 양성균주를 대상으로 multiplex PCR을 시행하였다. 그 결과 전체 69주 모 두 해당 내성 유전자가 정확하게 검출되었고 비특이적 증폭 반 응은 없었다. 위양성 및 비특이 증폭 반응의 유무를 확인하기 위해 그람양성균주 7주, 그람음성균주 63주, 효모 3주를 포함 한 총 71주의 카바페넴 감수성 균주를 대상으로 시험하였고 그 결과 모두 음성이었으며 비특이적 증폭물은 확인되지 않았다.

\section{DISCUSSION}

$\mathrm{CRE}$ 의 주요 내성기전은 class $\mathrm{A}$, metallo- $\beta$-lactamase (MBL, class B) 및 oxacillinase (class D) 카바페넴 분해효소의 생성에 의한 항균제의 불활성화이다. 특히 Klebsiella pneumoniae carbapenemase (KPC), New Delhi metallo- $\beta$-lactamase (NDM), Verona integron-encoded metallo- $\beta$-lactamase (VIM), imipenemase (IMP), oxacillinase (OXA)-48 등의 발생이 증가하 여 문제가 되고 있다[11,12]. 국내에서도 $\mathrm{CPE}$ 의 검출이 지속적 으로 증가하고 있으며 tigecycline과 colistin 등을 제외한 대부 분의 항생제에 내성을 보이는 등 다른 내성균에 비해 치명적이 고 확산 우려가 크기 때문에 2017년 6월부터 제3군 감염병으로 지정하여 전수조사를 시행하고 있다[13].

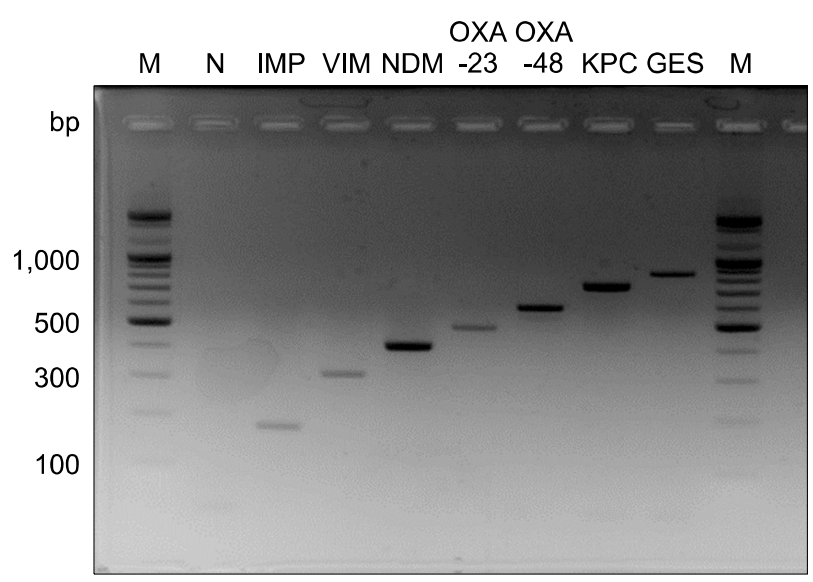

Fig. 1. Multiplex PCR for the detection of seven carbapenemaseproducing Enterobacteriaceae genes. Abbreviations: M, molecular weight marker; N, negative control. Lane: IMP (180 bp), VIM (306 bp), NDM (410 bp), OXA-23 (505 bp), OXA-48 (602 bp), KPC (747 $\mathrm{bp})$, and GES (855 bp).

Table 3. Primers used in this study

\begin{tabular}{|c|c|c|c|}
\hline \multicolumn{2}{|c|}{ Gene } & \multirow{2}{*}{$\begin{array}{c}\text { Primer sequence }\left(5^{\prime}-3^{\prime}\right) \\
\text { GGTGGTTGTTTTATTAAACCGTA }\end{array}$} & \multirow{2}{*}{$\frac{\text { Product size }(\mathrm{bp})}{180}$} \\
\hline IMP & Forward & & \\
\hline & Reverse & TTTAACCGCCTGCTCTAATG & \\
\hline \multirow[t]{2}{*}{ VIM } & Forward & TGGTGATGAGTTGCTTTTGA & 306 \\
\hline & Reverse & GCAGCACCAGGATAGAAGAG & \\
\hline \multirow[t]{2}{*}{ NDM } & Forward & GCAGCACACTTCCTATCTCG & 410 \\
\hline & Reverse & CGGTGATATTGTCACTGGTGT & \\
\hline \multirow[t]{2}{*}{ OXA-23 } & Forward & CAGAATATGTGCCAGCCTCT & 505 \\
\hline & Reverse & ATTTTTCCATCTGGCTGCTC & \\
\hline \multirow[t]{2}{*}{ OXA-48 } & Forward & GCGTAGTTGTGCTCTGGAAT & 602 \\
\hline & Reverse & GGGCATATCCATATTCATCG & \\
\hline \multirow[t]{2}{*}{$\mathrm{KPC}$} & Forward & TGTCACTGTATCGCCGTCTA & 747 \\
\hline & Reverse & AGACGACGGCATAGTCATTT & \\
\hline \multirow[t]{2}{*}{ GES } & Forward & CGCTTCATTCACGCACTATT & 855 \\
\hline & Reverse & GTCCGTGCTCAGGATGAGTT & \\
\hline
\end{tabular}


국가 또는 기관별로 차이가 있으나 Clinical and Laboratory Standards Institute (CLSI)에서는 카바페넴 항균제 중 한 가지 이상에서 중간내성 또는 내성인 균주를 $\mathrm{CPE}$ 선별기준으로 정 하고 있다[14]. MHT는 표현형 검사법으로 검사법이 간편하여 검사실에서 $\mathrm{CPE}$ 확정시험으로 널리 사용되고 있으나 CTX-M $\mathrm{ESBL}$ 또는 $\mathrm{AmpC}$ 에 porin 소실이 동반된 경우 위양성을 보이 는 경우가 있어 특이도가 낮은 편이다[15]. CIT의 경우 카바페 넴분해효소 생성 그람음성균을 검출하기 위해 고안되었으며 MHT에 비해 민감도 및 특이도가 높은 장점이 있다.

분자생물학적 기법은 카바페넴 유전자를 정확하게 동정하는 표준시험법으로 $\mathrm{PCR}$ 을 통해 정확한 유전형의 종류를 확인할 수 있으나 아직 표준화된 검사법이 없어 각 연구자들이 in-house PCR-based method법을 이용하고 있다. Poirel 등[16] 은 IMP, VIM, NDM, SPM, AIM, DIM, GIM, SIM KPC, BIC와 OXA-48 등 총 11 개의 유전형을 3개의 반응물로 구성한 multiplex PCR법을 고안하여 보고하였다. 이 방법은 많은 종류의 유 전형을 검출할 수 있다는 장점이 있지만 PCR을 3 번 수행해야 하는 번거로움이 있고 국내에서는 잘 발견되지 않는 유전형이 포함되어 있는 단점이 있다. 국내 질병관리본부에서는 Poirel 등[16]이 보고한 검사법을 변형하여 국내에서 검출되지 않는 유전형을 제외한 $\mathrm{KPC}, \mathrm{NDM}, \mathrm{OXA}-48, \mathrm{VIM}$ 및 IMP가 포함된 multiplex PCR법을 소개하고 있다.

본 연구에서 개발된 multiplex PCR법은 질병관리본부에서 제안한 검사법에서 검출 가능한 5개 유전자에 추가로 OXA-23 과 GES를 검출할 수 있으며 primer를 새롭게 고안하여 총 7종 의 유전형을 한번에 검출할 수 있다는 장점이 있다. 국내 $\mathrm{CPE}$ 분리 빈도를 살펴보면 2012년 질병관리본부 조사 결과 총 44주 의 $\mathrm{CPE}$ 중 NDM-1, KPC, VIM, IMP, GES-5 등이 확인되었다 고 보고하였다[17]. 또한 Park 등[13]은 2014년 국내 CPE의 실 제 조사한 결과를 발표하였는데 GES-5 (0.6\%), IMP (3.4\%), KPC (23.6\%), NDM-1 (21.3\%), OXA-48 (2.3\%) 및 VIM (11.5\%) 등이 분리되었음을 보고하였다. 균종별로는 Citrobacter freundii (4.6\%), Escherichia coli (4.0\%), Enterobacter spp. (17.2\%), Klebsiella oxytoca (8.0\%), K. pneumoniae (59.8\%) 등 이 높은 빈도로 분리되었음을 보고하였다.

질병관리본부에서 제공해주는 변형된 multiplex PCR법만으 로는 증가하고 있는 GES 유전형을 검출하는 데 한계가 있으며 이로 인해 더 많은 $\mathrm{CPE}$ 를 놓칠 수 있다고 생각한다. 또한 $\mathrm{CPE}$ 에서 OXA-23형 유전자의 검출 빈도는 높지 않지만 내성 유전 자를 전달할 수 있는 특징 때문에 차후 검출률이 증가할 수 있 으므로 현재 질병관리본부에서 제안하고 있는 검사법의 보완 이 필요할 것이라고 생각한다.

최근 검사실 내 $\mathrm{CPE}$ 의 빠른 진단을 위해 검체 내에서 바로 검출이 가능한 실시간 중합효소반응 검사법이 이용되고 있다. Check-Direct CPE (Check-Points, Wageningen, The Netherlands)
와 CRE ELITe $\mathrm{MGB}^{\circledR}$ (ELITechGroup, Puteaux, France)의 경 우 각각 4 개의 유전형(KPC, OXA-48, VIM/NDM)과 5 개의 유 전형(KPC, NDM, VIM, IMP, OXA-48)을 검출할 수 있도록 고 안되어 있다. Xpert ${ }^{\circledR}$ Carba-R (Cepheid, Sunnyvale, CA, USA) 의 경우 미세유체칩이 적용된 카트리지를 이용한 실시간 중합 효소반응 검사법으로 $\mathrm{KPC}, \mathrm{NDM}, \mathrm{VIM}, \mathrm{IMP}, \mathrm{OXA}-48$ 총 5 개 의 유전형을 검출할 수 있도록 고안되어 있다. 위와 같은 검사 법들은 검체 내에서 직접 유전형의 검출이 가능하기 때문에 균 주 배양 및 핵산 분리에 걸리는 시간을 단축할 수 있어 검사실 내 환자의 빠른 진단에 유용하게 사용되고 있다[18]. 본 연구에 서 개발된 multiplex PCR법은 균주를 배양한 후 핵산을 분리하 는 과정이 요구되기 때문에 위의 검사법들에 비해 검출 시간이 오래 걸린다는 한계점을 가진다. 이것은 차후 추가적인 연구를 통해 개선되어야 할 것이라고 생각한다.

본 연구에서 개발된 multiplex PCR은 총 7종의 $\mathrm{CPE}$ 유전형 을 한 번에 검출할 수 있도록 고안되었으며 $\mathrm{CPE}$ 에만 특이적으 로 적용 가능한 방법임을 확인하였다. 이러한 검사법의 활용은 매년 빠르게 증가하고 있는 $\mathrm{CPE}$ 의 정확한 검출이 가능하여 원 내 감시체계 구축 및 감염관리에도 큰 도움을 줄 수 있을 것이 라고 생각한다.

\section{ACKNOWLEDGMENTS}

This research was supported by a fund (2017-ER5402-01) by Research of Korea Centers for Disease Control and Prevension.

\section{REFERENCES}

1. Pitout JD. Infections with extended-spectrum beta-lactamaseproducing Enterobacteriaceae: changing epidemiology and drug treatment choices. Drugs 2010;70:313-33.

2. Nordmann P, Naas T, Poirel L. Global spread of carbapenemaseproducing Enterobacteriaceae. Emerg Infect Dis 2011;17:1791-8.

3. Gupta N, Limbago BM, Patel JB, Kallen AJ. Carbapenem-resistant Enterobacteriaceae: epidemiology and prevention. Clin Infect Dis 2011;53:60-7.

4. Nordmann P, Cuzon G, Naas T. The real threat of Klebsiella pneumoniae carbapenemase-producing bacteria. Lancet Infect Dis 2009;9:228-36.

5. Tzouvelekis LS, Markogiannakis A, Psichogiou M, Tassios PT, Daikos GL. Carbapenemases in Klebsiella pneumoniae and other Enterobacteriaceae: an evolving crisis of global dimensions. Clin Microbiol Rev 2012;25:682-707.

6. Jeong SH, Song W, Bae IK, Kim HS, Kim JS, Park MJ, et al. Broth microdilution methods using B-lactamase inhibitors for the identification of Klebsiella pneumoniae carbapenemases and metallo- $\beta$-lactamases in Gram-negative bacilli. Ann Clin Lab Sci 2014;44:49-55.

7. Anderson KF, Lonsway DR, Rasheed JK, Biddle J, Jensen B, McDougal LK, et al. Evaluation of methods to identify the Klebsiella pneumoniae carbapenemase in Enterobacteriaceae. J 
Clin Microbiol 2007;45:2723-5.

8. Pasteran F, Mendez T, Rapoport M, Guerriero L, Corso A. Controlling false-positive results obtained with the Hodge and Masuda assays for detection of class a carbapenemase in species of enterobacteriaceae by incorporating boronic acid. J Clin Microbiol 2010;48:1323-32.

9. Yoon EJ, Yang JW, Kim JO, Lee H, Lee KJ, Jeong SH. Carbapenemase-producing Enterobacteriaceae in South Korea: a report from the National Laboratory Surveillance System. Future Microbiol 2018;13:771-83.

10. Yoon EJ, Kim JO, Yang JW, Kim HS, Lee KJ, Jeong SH, et al. The bla $a_{\mathrm{OXA}-23}$-associated transposons in the genome of Acinetobacter spp. represent an epidemiological situation of the species encountering carbapenems. J Antimicrob Chemother 2017;72:2708-14.

11. Bush K. Alarming $\beta$-lactamase-mediated resistance in multidrugresistant Enterobacteriaceae. Curr Opin Microbiol 2010;13:558-64.

12. Gasink LB, Edelstein PH, Lautenbach E, Synnestvedt M, Fishman NO. Risk factors and clinical impact of Klebsiella pneumoniae carbapenemase-producing $K$. pneumoniae. Infect Control Hosp Epidemiol 2009;30:1180-5.
13. Park JW, Lee EJ, Lee DH. Status of carbapenemase producing Enterobacteriaceae in Korea, 2014. Public Health Wkly Rep 2016;9:9-13.

14. CLSI. Performance standards for antimicrobial susceptibility testing. CLSI document M100-S23. Wayne, PA: Clinical and Laboratory Standards Institute; 2013.

15. Doumith M, Ellington MJ, Livermore DM, Woodford N. Molecular mechanisms disrupting porin expression in ertapenemresistant Klebsiella and Enterobacter spp. clinical isolates from the UK. J Antimicrob Chemother 2009;63:659-67.

16. Poirel L, Walsh TR, Cuvillier V, Nordmann P. Multiplex PCR for detection of acquired carbapenemase genes. Diagn Microbiol Infect Dis 2011;70:119-23.

17. You JS. Emergence and characteristics of carbapenemase-producing Enterobacteriaceae (CPE) in Korea, 2012. Public Health Wkly Rep 2013;6:425-8.

18. Huang TD, Bogaerts P, Ghilani E, Heinrichs A, Gavage P, Roisin $\mathrm{S}$, et al. Multicentre evaluation of the Check-Direct $\mathrm{CPE}^{\mathrm{R}}$ assay for direct screening of carbapenemase-producing Enterobacteriaceae from rectal swabs. J Antimicrob Chemother 2015;70:1669-73.

\title{
$=$ 국문초록=
}

\section{카바페넴분해효소 생성 장내세균 검출을 위한 Multiplex PCR의 개발 및 평가}

\author{
${ }^{1}$ 세명대학교 임상병리학과, ${ }^{2}$ 신라대학교 치위생학과, ${ }^{3}$ 인제대학교 의과대학 진단검사의학교실, \\ ${ }^{4}$ 인제대학교 의과대학 백인제기념임상의학연구소, ${ }^{5}$ 경상대학교 의과대학 진단검사의학교실, \\ ${ }^{6}$ 울산대학교 의과대학 울산대학교병원 진단검사의학교실 \\ 김시현 ${ }^{1}$, 배일권 $^{2}$, 김나영 ${ }^{3,4}$, 송새암 $^{3}$, 김선주 ${ }^{5}$, 정윤성 ${ }^{6}$, 신정환 $^{3,4}$
}

배경: 다양한 임상검체에서 카바페넴분해효소 생성 장내세균(carbapenemase-producing Enterobacteriace, $\mathrm{CPE}$ )의 분리가 증가하고 있다. $\mathrm{CPE}$ 감염증은 치사율이 높고, 집단 발병의 가능성이 높아 지속적인 감시가 필수적이다. 저자들은 $\mathrm{CPE}$ 주요 유전자들을 한 번에 검출하기 위한 multiplex PCR을 개발하고 이를 평가하고자 하였다.

방법: 총 7종의 내성 유전자를 동시에 검출하기 위한 시발체를 새롭게 디자인하고 PCR 조건을 설정하였다. 주요 카바페 넴분해효소인 KPC, IMP, VIM, NDM-1, GES, OXA-23 및 OXA-48 유전자를 대상으로 하였다. 각 유전자의 증폭 산물은 $100 \mathrm{bp}$ 이상의 차이가 나도록 고안하였다. 개발된 multiplex PCR은 총 69 주의 $\mathrm{CPE}$ 양성 임상분리균주를 이용하여 평가하 고, 비특이적 증폭에 의한 위양성 가능성의 배제를 위해 71주의 카바페넴 감수성 균주로 확인하였다.

결과: 본 연구에서 개발한 시발체 및 PCR 조건을 이용하여 실험한 결과 CPE 내성 유전자인 $\mathrm{KPC}$ 양성 14 주, IMP 양성 13 주, OXA-23 양성 12주, OXA-48 양성 11주, VIM 양성 9주, GES 및 NDM 양성 각 5 주 등 총 69 주 모두에서 CPE 유전자 의 검출이 가능함을 확인하였다. 카바페넴 감수성 균주를 이용한 특이성 확인 시험에서 Enterococcus faecalis, Escherichia coli, Klebsiella pneumoniae, Acinetobacter baumannii, Pseudomonas aeruginosa 등을 포함한 총 71주의 다양한 그람양성 및 음성균주 모두에서 음성임을 확인하였다.

결론: 본 연구에서 개발된 multiplex PCR은 총 7종의 $\mathrm{CPE}$ 유전형을 한 번에 검출할 수 있어 $\mathrm{CPE}$ 확인 시험에 유용할 것으로 생각한다. [Ann Clin Microbiol 2019;22:9-13] 